\title{
Role of Glucagon-like Peptide-1 Analogues on Obesity and Type-II Diabetes Mellitus: A Review
}

\author{
Maheswary L A*1, Dr. Silvia Navis ${ }^{2}$, Anusree $S^{3}$, Dr. Prasobh G. $R^{4}$ \\ ${ }^{1}$ Fourth Year B.Pharm Student, Sree Krishna College of Pharmacy and Research Centre, Parassala, Trivandrum, Kerala, India. \\ ${ }^{2}$ Head Of Department of Pharmacology, Sree Krishna College of Pharmacy and Research Centre, Parassala, Trivandrum, Kerala, India. \\ ${ }^{3}$ Assistant Professor, Department of Pharmacology, Sree Krishna College of Pharmacy and Research Centre, Parassala, Trivandrum, Kerala, India. \\ ${ }^{4}$ Principal, Sree Krishna College of Pharmacy and Research Centre, Parassala, Trivandrum, Kerala, India.
}

*Corresponding author's E-mail: ashokkumar97445@gmail.com

Received: 19-07-2020; Revised: 28-09-2020; Accepted: 06-10-2020; Published on: 20-10-2020. ABSTRACT

Obesity and diabetes are closely related to each other as about $80 \%$ diabetics are obese; weight reduction in such obese patients produces improvement in the diabetic state. Diabetes is caused by the absence of insulin secretion due to either the progressive or marked inability of the $\beta$-Langerhans islet cells of the pancreas to produce insulin, or due to defects in insulin uptake in the peripheral tissue. Obesity is linked to many medical, psychological, and social conditions, the most devastating of which may be type-II diabetes mellitus. Obesity increases the risk of T-IIDM. Increased release of Non-esterified fatty acids is observed in T-IIDM and in obesity, and it is associated with insulin resistance in both conditions. Shortly after an acute increase of plasma NEFA levels in humans, insulin resistance starts to develop. Thus, targeting the incretin system has become an important therapeutic approach for treating T-IIDM. Incretinmimetics are a new class of antidiabetes drugs. They bind to and activate GLP-1 receptors on pancreatic beta-cells following which insulin secretion and synthesis are initiated. Glucagon-like peptide-1 receptor agonists or incretinmimetics, are agonists of the GLP-1 receptor used for the treatment of T-IIDM, in addition to that it has a good and beneficial effect on weight loss and one of their advantages over older insulin secretagogues, such as sulfonylureas or meglitinides, is that they have a lower risk of causing hypoglycaemia. The present article is a basic review of various relevant literatures for efficacy, safety and clinical applicability of Glucagon-like peptide-1 analogues on T-IIDM and weight management in adults with overweight or obesity. The development of new therapies for the treatment of T-IIDM that in addition to maintaining glycaemic control, which could reduce body weight and hypoglycaemia risk may help in patient management. The review concludes that Glucagon-like peptide-1 analogues also had a good effect on the weight loss so that obese patients could benefit from it, whether they had diabetes or not. Thus, new approaches in managing and preventing diabetes in obese individuals must be studied and investigated based on these facts.

Keywords: Diabetes mellitus, Obesity, incretins, GLP-1 analogues

QUICK RESPONSE CODE $\rightarrow$

DOI:

10.47583/ijpsrr.2020.v64i02.017

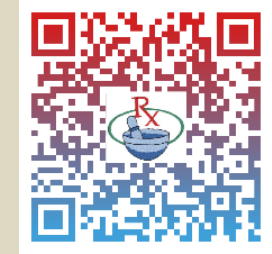

DOI link: http://dx.doi.org/10.47583/ijpsrr.2020.v64i02.017

\section{INTRODUCTION}

besity is a common finding in Type-II diabetes mellitus (T-IIDM). There is impaired insulin sensitivity of peripheral tissues such as muscle and fat cells to the action of insulin in obese individuals (insulin resistance). Obesity increases the risk of T-IIDM, cardiovascular disease, cancer, and premature death. Pharmacological factor involved in obesity and diabetes includes lipoprotein lipase, having a central role in the metabolism of both triglyceride rich particles and HighDensity Lipoproteins (HDL). Lipoprotein lipase is determinant of serum triglyceride and HDL concentrations. It is a well-known fact that if the individuals are overweight or obese, they are at greater risk of developing T-IIDM, particularly if they have excess weight around their tummy (abdomen). Abdominal fat causes fat cells to releases 'pro- inflammatory' chemicals, which can make the body less sensitive to the insulin it produces by disrupting the function of insulin responsive cells and their ability to respond to insulin. This is known as insulin resistance - a major trigger for T-IIDM. Having excess abdominal fat (i.e. a large waistline) is known as central or abdominal obesity, a particularly high-risk form of obesity. Obesity is also thought to trigger changes to the body's metabolism. These changes cause fat tissue (adipose tissue) to release fat molecules into the blood, which can affect insulin responsive cells and lead to reduced insulin sensitivity. Another theory put forward by scientists into how obesity could lead T-IIDM is that obesity causes prediabetes, a metabolic condition that almost always develops into TIIDM. The links between obesity and T-IIDM are firmly established without the intervention of a healthy diet and appropriate exercise, obesity can lead to T-IIDM over a relatively short period of time. The good news is that by reducing the body weight, by even a small amount, can help to improve the body's insulin sensitivity and lowers the risk of developing cardiovascular and metabolic conditions such as T-IIDM, heart disease and types of cancer. According to the NHS, a $5 \%$ reduction in body weight followed up by regular moderate intensity exercise could reduce T-IIDM risk by more than $50 \%$. The influence 
of obesity on T-IIDM risk is determined not only by the degree of obesity but also by where the fat accumulates. Increased upper body fat including visceral adiposity, as reflected in increased abdominal girth or waist-to hip ratio, is associated with the metabolic syndrome, T-IIDM, and cardiovascular disease, although underlying mechanisms remain uncertain ${ }^{1}$. Thus, careful consideration should be given to the selection of therapies for managing T-IIDM. In particular, incretin-based therapies [Glucagon-like peptide-1 receptor agonists (GLP-1RAs), specifically] can help by offering weight reduction, blood pressure reduction, and reduced hypoglycaemia in addition to glycaemic control. ${ }^{2}$

\section{Diabetes mellitus}

In 2019, a total of 463 million people are estimated to be living with diabetes, representing $9.3 \%$ of the global adult population. The prevalence is higher in urban $(10.8 \%)$ than rural $(7.2 \%)$ areas. The prevalence of diabetes in women in 2019 is estimated to be $9.0 \%$, and $9.6 \%$ in men. One in two (50.1\%) people living with diabetes do not know that they have diabetes. At a country level, China (116 million), India (77 million), and the United States of America (31 million) are those with the highest numbers of people living with diabetes in 2019. It is very difficult to reach an accurate measure of prevalence of diabetes for two main reasons: i) The standards and methods of data collection varying widely in different parts of the world; the country's most affected by this epidemic in the year 2025 will be China, India and the USA, ii) Even today there is a large population (almost 50\%) of the patients remaining undiagnosed. ${ }^{3}$

Diabetes was first documented by the Egyptian, in a medical text written around 1552 B.C, called the Ebers Papyrus, describes a condition of passing too much urine and is characterized by weight loss and polyuria. It was the Greek physician Aretaeus who coined the term Diabetes Mellitus (DM). In Greek, diabetes means "to pass through" and mellitus is the Latin word for honey (referring to sweetness). In 1936, the distinction between Type-I and Type-Il diabetes mellitus was clearly made. ${ }^{4}$

DM is a chronic disorder that can alter carbohydrate, protein, and fat metabolism. It is caused by the absence of insulin secretion due to either the progressive or marked inability of the $\beta$-Langerhans islet cells of the pancreas to produce insulin, or due to defects in insulin uptake in the peripheral tissue. $^{5}$

Once the body absorbs simple sugars, it usually converts them all into glucose, which is an important source of fuel for the body. Glucose is the sugar that is transported through the bloodstream and taken up by cells. Blood "sugar" really means blood glucose. The levels of glucose in the blood vary normally throughout the day. They rise after a meal and return to pre-meal levels within about 2 hours after eating. Once the levels of glucose in the blood return to pre-meal level, insulin production decreases. If the body does not produce enough insulin to move the glucose into the cells, or if the cells stop responding normally to insulin, the resulting high levels of glucose in the blood and the inadequate amount of glucose in the cells together produce the symptoms and complications of diabetes. ${ }^{6}$

It is important to individualize goals for patients regarding target blood glucose values, the table: 1 shows the lists recommendations from the American Diabetes Association (ADA) and American Association of Clinical Endocrinologists (AACE) ${ }^{7,8}$

Table 1: DM is broadly classified under two categories, which include Type-I and Type-Il diabetes mellitus.

Recommendations for target glucose levels:

\begin{tabular}{c|c}
\hline $\begin{array}{c}\text { ADA Recommendation } \\
\text { Non pregnant Adults }\end{array}$ & \\
\hline $\begin{array}{c}\text { Preprandial blood glucose } \\
\text { levels }\end{array}$ & $\begin{array}{c}80-130 \mathrm{mg} / \mathrm{dL}(4.4-7.2 \\
\mathrm{mmol} / \mathrm{L})\end{array}$ \\
\hline $\begin{array}{c}\text { Peak postprandial levels } \\
\text { Hemoglobin } \mathrm{A}_{1 \mathrm{c}}\end{array}$ & $<180 \mathrm{mg} / \mathrm{dL}(<10.0 \mathrm{mmol} / \mathrm{L})$ \\
\hline $\begin{array}{c}\text { Pregnant women with } \\
\text { preexisting T-IDM or T-IIDM, } \\
\text { gestational diabetes }\end{array}$ & $<7 \%(53 \mathrm{mmol} / \mathrm{mol})$ \\
\hline Fasting plasma glucose & $<95 \mathrm{mg} / \mathrm{dL}(5.3 \mathrm{mmol} / \mathrm{L})$ \\
\hline 1-hr postprandial & $<140 \mathrm{mg} / \mathrm{dL}(7.8 \mathrm{mmol} / \mathrm{L})$ \\
\hline 2-hr postprandial & $<120 \mathrm{mg} / \mathrm{dL}(6.7 \mathrm{mmol} / \mathrm{L})$ \\
\hline Hemoglobin A $1 \mathrm{c}$ & $6 \%-6.5 \%(42-48 \mathrm{mmol} / \mathrm{mol})$ \\
\hline AACE Recommendation & \\
\hline Non pregnant Adults & \\
\hline Fasting blood glucose & $<110 \mathrm{mg} / \mathrm{dL}(6.1 \mathrm{mg} / \mathrm{dL})$ \\
\hline 2-hr postprandial & $<140 \mathrm{mg} / \mathrm{dL}(7.8 \mathrm{mmol} / \mathrm{L})$ \\
\hline Hemoglobin $\mathrm{A}_{1 \mathrm{c}}$ & $<6.5 \%(48 \mathrm{mmol} / \mathrm{mol})$ \\
\hline
\end{tabular}

\section{Type-I diabetes mellitus}

Type-I diabetes mellitus (T-IDM), previously called insulindependent diabetes mellitus (IDDM) or juvenile onset diabetes. The body's immune system attacks the insulinproducing cells of the pancreas, and more than $90 \%$ of them are permanently destroyed. Thus, the pancreas produces little or no insulin. Only about 5 to $10 \%$ of all people with diabetes have Type-I disease. Most people who have T-IDM develop the disease before age 30, although it can develop later in life. Occurs most commonly in children, but it can sometimes also appear in adult age groups, particularly in those in their late thirties and early forties. Patients with T-IDM are generally not obese and frequently present with an emergency status known as diabetes ketoacidosis. ${ }^{6}$

The etiology of T-IDM can be explained by damage to the pancreatic cells due to environmental or infectious agents. In individuals who are susceptible to genetic alterations, the immune system is triggered to produce an immune 
response against altered $\beta$-cells, or against molecules in $\beta$ cells that are similar to viral proteins. Approximately $80 \%$ of patients with T-IDM show circulating islet cell antibodies, and most of these patients have anti-insulin antibodies before receiving insulin therapy. The major factor in the pathophysiology of T-IDM is considered to be autoimmunity. There is a strong relationship between TIDM and other autoimmune diseases such as Graves' disease, Hashimoto's thyroiditis, and Addison's disease. When these diseases are present, the prevalence rates of T-IDM increase. Vitamin D plays a major role in the pathogenesis and prevention of T-IDM. In addition, vitamin D deficiency is an independent predictor of the development of coronary artery disease in individuals with T-IDM. Furthermore, another study has proved that vitamin $D$ deficiency in T-IDM may predict all causes of mortality. ${ }^{5}$

\section{Type-II diabetes mellitus}

Type-II diabetes mellitus (T-IIDM), previously called noninsulin-dependent diabetes mellitus (NIDDM) or adultonset diabetes. The body develops resistance to the effects of insulin, so there is not enough insulin to meet the body's needs. As T-IIDM progresses, the insulin producing ability of the pancreas decreases. T-IIDM was once rare in children and adolescents but has recently become more common. It is usually begins in people older than 30 and becomes progressively more common with age. About $26 \%$ of people older than 65 have T-IIDM. ${ }^{6}$

It has a different pathophysiology and etiology as compared to T-IDM. The existence of many new factors for example, the increased prevalence of obesity among all age groups and poor diet, and urbanization, means that the number of patients diagnosed with T-IIDM is rising. TIIDM is described as a combination of low amounts of insulin production from pancreatic $\beta$-cells and peripheral insulin resistance. Insulin resistance leads to elevated fatty acids in the plasma, causing decreased glucose transport into the muscle cells, as well as increased fat breakdown, subsequently leading to elevated hepatic glucose production. Insulin resistance and pancreatic $\beta$-cell dysfunction must occur simultaneously for T-IIDM to develop. Anyone who is overweight or obese has some kind of insulin resistance, but diabetes only develops in those individuals who lack sufficient insulin secretion to match the degree of insulin resistance. Insulin in those people may be high, yet it is not enough to normalize the level of glycaemia. ${ }^{5}$

\section{Obesity}

Obesity has become a major topic of medical research in the world. In June 2013, the American medical association first declared obesity a disease. The disease in which no obvious endocrine, metabolic disease and another pathogen can be found is called simple obesity. Simple obesity is a nutritional disorder disease in which the longterm Energy Intake (EI) exceeds the consumption of the human body, resulting in excessive accumulation of fat and excess weight. It is a serious, chronic, relapsing disease of energy regulation with strong genetic and early-life environmental determinants. ${ }^{9}$

The World Health Organization (WHO) defines obesity and overweight as excessive or abnormal fat accumulation that may impair a person's health, which usually exceeds $20 \%$ or more of an individual's ideal body weight. Overweight and obesity can be classified by using a simple index of weight-for-height calculations, referred to as the Body mass index (BMI). ${ }^{10}$

Table 2: Classifying or grading of the level of obesity by utilizing the BMI:

\begin{tabular}{|c|c|}
\hline Level of Obesity & Corresponding BMI \\
\hline Overweight & $\geq 25 \mathrm{~kg} / \mathrm{m}^{2}$ \\
\hline Obese & $\geq 30 \mathrm{~kg} / \mathrm{m}^{2}$ \\
Morbidly obese & $\geq 40 \mathrm{~kg} / \mathrm{m}^{2}$ \\
\hline
\end{tabular}

Obesity is considered a health disaster in both developed and developing countries. The prevalence is escalating significantly in many nations worldwide. This pandemic needs to be stopped if the economic costs, social hazards, morbidity, and mortality of the disease are considered. ${ }^{5}$ Obesity is a chronic metabolic disease caused by many factors and is a risk factor for many diseases, such as hypertension, coronary heart disease, ischemic stroke, diabetes and gout. At the same time obese patients are more likely to have mobility difficulties accompanied by joint pain, swelling, muscle soreness, and other uncomfortable symptoms. Physical discomfort reduces the number of activities of obese people, causing fear of activities and affecting normal social functions. However, impaired social functions, anxiety and other adverse psychological emotions thus affecting their mental health. ${ }^{9}$

More recently, the tripling in the prevalence of T-IIDM worldwide has been attributed to the increase in the rate of obesity. The prevalence of T-IIDM is an increasing public health problem globally, and targeted behaviour like physical exercise and healthy eating are important in both the prevention and treatment of DM. The first-line treatment of obesity is still lifestyle modification, but the limitation is poor long-term compliance and control. Pharmaceutical intervention should be seen as an additional therapeutic aid to such lifestyle changes. ${ }^{11}$

The long-term goal of obesity treatment is to reduce body weight by $5-10 \%$, maintain a $\mathrm{BMI}<25 \mathrm{~kg} / \mathrm{m}^{2}$, lower blood pressure, blood glucose, and lipid levels, and other risk factors. Current obesity treatment measures include: ${ }^{12}$

\section{Lifestyle intervention}

\section{Drug intervention}

3. Surgical treatment 


\section{Mechanism linking obesity and type-II diabetes mellitus}

The increased prevalence of obesity these days has drawn attention to the worldwide significance of this problem. In a large survey conducted by the National Centre for Health Statistics, the prevalence of DM in overweight individuals was above $80 \%$, while obese patients had a $49 \%$ prevalence of diabetes. In contrast to this, the prevalence of diabetes in the group of patients with a BMI $<25 \mathrm{~kg} / \mathrm{m}^{2}$ was the lowest at $8 \%$. Thus, more effort should be taken to combat obesity, as obesity is a modifiable risk factor for the development of diabetes. Both T-IIDM and obesity are associated with insulin resistance. Obesity is considered the most important factor in the development of metabolic diseases. Adipose tissue affects metabolism by secreting hormones, glycerol, pro-inflammatory substances, and by releasing Non-esterified fatty acids (NEFAs). The cornerstone factor affecting insulin insensitivity is the release of NEFAs. Increased release of NEFAs is observed in T-IIDM and in obesity, and it is associated with insulin resistance in both conditions. Shortly after an acute increase of plasma NEFA levels in humans, insulin resistance starts to develop. Throughout the natural history of T-IIDM, endothelial dysfunction is accompanied with obesity or insulin resistance in diabetes and prediabetes conditions (this includes people with impaired glucose tolerance or impaired fasting glucose). In order to develop insulin resistance and obesity, thereby causing T-IIDM, $\beta$-cells should not be able to compensate fully for decreased insulin sensitivity. NEFAs that are secreted from adipose tissue in obese people may lead to the hypothesis that insulin resistance and $\beta$-cell dysfunction are most likely linked. ${ }^{5}$

\section{Therapy}

\section{Incretinmimetics (GLP-1 anagloues)}

Targeting the incretin system has become an important therapeutic approach for treating T-IIDM. Furthermore, incidence of hypoglycaemia is relatively low with these treatments (except when used in combination with a sulfonylurea) because of their glucose-dependent mechanism of action. The development of new therapies for the treatment of T-IIDM that, in addition to maintaining glycaemic control, could reduce body weight and hypoglycaemia risk 13, 14, may help with patient management. ${ }^{2}$

\section{Incretins}

In 1932, Belgian physiologist Jean La Barre used the word "incretin" for a gut hormone, which stimulates the endocrine pancreas including insulin release. He also proposed that such incretins could be used as a treatment for DM. ${ }^{15}$

Incretins are the group of metabolic hormones that stimulate a decrease in blood glucose levels. Incretins are released after eating and augment the secretion of insulin released from pancreatic beta-cells of the islets of Langerhans by a blood glucose-dependent mechanism.
Some incretins (GLP-1) also inhibit glucagon release from the alpha cells of the islets of Langerhans. In addition, they slow the rate of absorption of nutrients into the bloodstream by reducing gastric emptying and may directly reduce food intake. ${ }^{16}$

The incretin hormones are: ${ }^{17}$

1.Glucagon-like peptide-1 (GLP-1)

2.Gastric inhibitory peptide/Glucose-dependent insulinotropic polypeptide (GIP)

The most important effect of GLP-1 and GIP is their ability to potentiate glucose-induced insulin secretion from the pancreas the so-called incretin effect. In healthy subjects the incretin effect accounts for up to $70 \%$ of the insulin secreted in response to glucose ingestion. GLP-1 is a 30amino acid polypeptide processed from proglucagon in the endocrine L-cells distributed primarily in the mucosa of the distal part of the small intestine and colon. GIP is a 42amino acid polypeptide released from endocrine $\mathrm{K}$-cells found in the mucosa of the duodenum and upper jejunum. ${ }^{17}$

\section{Incretinmimetics}

The incretin effect has been defined as postprandial enhancement of insulin secretion by gut-derived factors. Similarly, Incretinmimetics and incretin effect amplifiers are the two different incretin-based treatment strategies developed for the treatment of T-IIDM. The Incretinmimetics produce effects very similar to those of natural incretin hormones. Anti-diabetic properties of these drugs have stimulated substantial clinical interest in the potential of incretin-based therapeutic agents as a means to control glucose homeostasis in T-IIDM patients. ${ }^{18}$

\section{Mechanism of action}

They work by copying, or mimicking, the functions of the natural incretin hormones in the body that helps to lower post-meal blood sugar levels (postprandial).

Their functions include 19

- Stimulating the release of insulin by the pancreas after eating, even before blood sugars start to rise.

- Inhibiting the release of glucagon by the pancreas. Glucagon is a hormone that causes the liver to release its stored sugar into the bloodstream.

- $\quad$ Slowing glucose absorption into the bloodstream by reducing the speed at which the stomach empties after eating, thus making to feel more satisfied after a meal.

\section{Glucagon-like peptide-1 analogues}

Also known as Glucagon-like peptide-1 receptor agonists (GLP-1RAs) or Incretinmimetics, are agonists of the GLP-1 receptor. This class of medications is used for the treatment of T-IIDM. ${ }^{20}$ But in addition to that it has a good and beneficial effect on weight loss. One of their advantages over older insulin secretagogues, such as 
sulfonylureas or meglitinides, is that they have a lower risk of causing hypoglycaemia. ${ }^{21} \mathrm{GLP}-1$ has a short duration of action, so to overcome this limitation several modifications either in the drug or the formulations are being developed. 22

\section{Pharmacological effects of GLP-1 RAs}

GLP-1 has a number of potentially beneficial effects in the setting of T-IIDM. Intravenous administration of exogenous GLP-1 to patients with T-IIDM was shown to reduce plasma glucose concentrations to the normal fasting range, even in patients who had an inadequate response to oral anti-hyperglycemic drugs. ${ }^{23}$

The pharmacology effects of GLP-1RAs are:

- Decreased glucagon concentrations

- Improved insulin sensitivity

- Decreased $\mathrm{HbA} 1_{c}$

- $\quad$ Slowed gastric emptying

- Decreased free fatty acid concentrations

- Decreased body weight
GLP-1RAs attenuates binge eating in obese patients, suggesting a role of GLP-1RAs in certain eating types. The psychology of eating distinguishes three main types of eating behaviors i.e. predominant external, emotional, and restrained eating patterns. All these three eating behavior patterns have been implicated in the risk of developing obesity. $^{24}$

\section{Side effects}

- Nausea (sometimes associated with vomiting)

- Diarrhoea

- Headaches

- Dizziness

- Increased sweating

- Indigestion

- Constipation

- Loss of appetite could contribute to the weight reducing effect. However, weight loss has also been observed when analyzing separately patients who do not report nausea. ${ }^{19,25}$

Table 3: Classification

\begin{tabular}{|c|c|c|c|c|c|}
\hline Generic name & Brand name(s) & $\begin{array}{c}\text { Approval } \\
\text { year }\end{array}$ & Dose & $\begin{array}{c}\text { Phase III } \\
\text { clinical trials }\end{array}$ & Company \\
\hline 1. Exenatide & $\begin{array}{l}\text { Byetta } \\
\text { Bydureon }\end{array}$ & $\begin{array}{l}2005 \\
2012\end{array}$ & $\begin{array}{l}5 \mu \mathrm{g} \text { or } 10 \mu \mathrm{g} \text { Twice daily. } \\
\qquad 2 \mathrm{mg} / \text { week }\end{array}$ & $\begin{array}{l}\text { AMIGO } \\
\text { DURATION }\end{array}$ & $\begin{array}{c}\text { Amylin } \\
\text { Astra Zeneca }\end{array}$ \\
\hline 2. Liraglutide & $\begin{array}{l}\text { Victoza } \\
\text { Saxenda }\end{array}$ & $\begin{array}{l}2010 \\
2014\end{array}$ & $\begin{array}{c}0.6 \mathrm{mg} \text { or } 0.8 \mathrm{mg} \text { or } 1.2 \mathrm{mg} \text { Daily } \\
0.6 \mathrm{mg}, 1.2 \mathrm{mg}, 1.8 \mathrm{mg}, 2.4 \mathrm{mg}, 3 \mathrm{mg} / \text { week }\end{array}$ & $\begin{array}{l}\text { LEAD } \\
\text { SCALE }\end{array}$ & Novo Nordisk \\
\hline 3. Lixisenatide & Lyxumia & 2013 & $10 \mu \mathrm{g}$ or $20 \mu \mathrm{g}$ Daily & GetGoal & Sanofi-aventis \\
\hline 4. Albiglutide & Tanzeum & 2014 & $30 \mathrm{mg}$ or $50 \mathrm{mg}$ & HARMONY & GSK \\
\hline 5. Dulaglutide & Trulicity & 2014 & $0.75 \mathrm{mg}$ or $1.5 \mathrm{mg} /$ week & AWARD & Eli lily \\
\hline 6. Semaglutide & $\begin{array}{c}\text { Ozempic } \\
\text { Rybelsus (oral) }\end{array}$ & $\begin{array}{l}2017 \\
2019\end{array}$ & $\begin{array}{l}0.75 \mathrm{mg} \text { or } 1.5 \mathrm{mg} / \text { week } \\
3 \mathrm{mg} \text { or } 7 \mathrm{mg} \text { or } 14 \mathrm{mg} \text { Daily }\end{array}$ & $\begin{array}{l}\text { SUSTAIN } \\
\text { PIONEER }\end{array}$ & Novo Nordisk \\
\hline
\end{tabular}

\section{RESULTS}

Table 4: Human studies

\begin{tabular}{|c|c|c|c|}
\hline GLP-1 Analogues & Author's name and year & Effects & Parameters measured \\
\hline \multirow{5}{*}{$\begin{array}{c}\text { Exenatide } \\
\text { (Chakraborti CK. } \\
\text { 2010) }\end{array}$} & Egan et al. 2003 & Decrease in $\mathrm{HbA1c}$ & HbA1c level \\
\hline & Mikhail N, 2006 & Decrease in $\mathrm{HbA1c}$ & HbA1c level \\
\hline & Lam and See, 2006 & Decrease in $\mathrm{HbA1c}$ and significant weight loss & HbA1c level, BMI \\
\hline & Ratner et al. 2006 & $\begin{array}{c}\text { Decrease in } \mathrm{HbA} 1 \mathrm{c} \text { and reduction in } \\
\text { body weight }\end{array}$ & HbA1c level and BMI. \\
\hline & Jones MC, 2007 & Decrease in $\mathrm{HbA1c}$ and significant weight loss. & HbA1c, FPG Levels and BMI \\
\hline \multirow{7}{*}{$\begin{array}{c}\text { Liraglutide } \\
\text { (James Crane and } \\
\text { Barbara } \\
\text { McGowan } \\
\text { 2016) } \text { (27 }^{27}\end{array}$} & Marre et al. 2009 & Change in $\mathrm{HbA} 1 \mathrm{c}$ and no significant weight loss & HbA1c level, BMI \\
\hline & Nauck et al. 2009 & Change in $\mathrm{HbA} 1 \mathrm{c}$ and significant weight loss & HbA1c level, BMI \\
\hline & Garber et al. 2009 & Change in $\mathrm{HbA} 1 \mathrm{c}$ and significant weight loss & HbA1c level, BMI \\
\hline & Zinman et al. 2009 & Change in $\mathrm{HbA} 1 \mathrm{c}$ and significant weight loss & HbA1c level, BMI \\
\hline & Russell-Jones et al. 2009 & Change in $\mathrm{HbA1C}$ and significant weight loss & HbA1c level, BMI \\
\hline & Buse et al. 2009 & Change in $\mathrm{HbA} 1 \mathrm{c}$ and significant weight loss & HbA1c level, BMI \\
\hline & Buse et al. 2013 & Change in $\mathrm{HbA1C}$ and significant weight loss & HbA1c level, BMI \\
\hline
\end{tabular}


Table 5: Animal studies

\begin{tabular}{|c|c|c|c|c|}
\hline SI No. & $\begin{array}{c}\text { GLP-1 } \\
\text { Analogues }\end{array}$ & $\begin{array}{c}\text { Author's name } \\
\text { and year }\end{array}$ & Effects & Parameters measured \\
\hline 1 & Exenatide & $\begin{array}{l}\text { Bronislava et al. } \\
\qquad 2004^{28}\end{array}$ & $\begin{array}{l}\text { Food intake, body weight, } \mathrm{HbA} 1 \mathrm{c} \text {, and } \\
\text { fasting plasma insulin concentration - } \\
\text { significantly reduced. }\end{array}$ & $\begin{array}{l}\text { Fasting plasma samples - } \\
\text { measurement of glucose, } \\
\text { insulin, lipids, and } \mathrm{HbA} 1_{c} \text { levels. }\end{array}$ \\
\hline 2 & Liraglutide & $\begin{array}{c}\text { Lotte Bjerre } \\
\text { Knudsen. } 2019^{29}\end{array}$ & $\begin{array}{l}\text { Weight loss in both normal and obese } \\
\text { rodents, also a marked effect to increase } \\
\text { diuresis and decrease water intake. }\end{array}$ & Body weight(BMI) \\
\hline
\end{tabular}

\section{DISCUSSIONS}

GLP-1 has attracted much attention from the medical community as an emerging drug due to its excellent function on hypoglycaemic affection. It is found that besides hypoglycaemic affection, it also had a good effect on the weight loss so that obese patients could benefit from it, whether they had diabetes or not. GLP-1 has a short survival time in the physiological state, with a halflife of only 1.5-2.0 minutes. Therefore, the more stable GLP-1 analogues with similar physiological effects has become a hot research topic. ${ }^{9}$

The first to be approved for sale is Exenatide, which is generally used as an indication of diabetes. Exenatide was isolated from the saliva of the lizard Heloderma suspectum. This lizard takes food four times a year and during feeding, EX-4, secreted in the saliva. Exenatide shares 53\% homology with native GLP-1 and binds to and activates GLP-1 receptors on pancreatic beta-cells following which insulin secretion and synthesis is initiated. Following SC administration, Exenatide is rapidly absorbed reaching peak concentrations in approximately 2 hours. In patients with T-IIDM with obesity, several trials have shown a statistically significant difference in weight loss from placebo. Exenatide is currently administered by injection. Due to its short half-life, it needs to be given twice a day. ${ }^{9}$, 17

Liraglutide is an acylated analogue of human GLP-1 and has $97 \%$ sequence homology to native GLP-1. The molecular structure of Liraglutide enables it to avoid being hydrolyzed by a DPP-4 enzyme with a half-life of about 13 hours. Liraglutide was approved internationally as a weight loss drug in 2014 and has shown that the weight effect persists for at least 12 months with the long-term use of Liraglutide in diabetics. This suggests that GLP-1 analogues have a relatively reliable long-term effect on obesity. But at the same time other studies have shown that increased heart rate due to Liraglutide may be harmful to patients with severe heart failure. Therefore, further studies are needed to assess the long-term effects of Liraglutide. However, Liraglutide has become an alternative, injectable option. At a dosage of $3.0 \mathrm{mg}$ oncedaily, Liraglutide is associated with clinically meaningful weight loss when used in combination with proper diet and exercise in overweight or obese patients. Weight-loss with
Liraglutide is sustainable and patients maintain their body weight up to two years after the treatment course. ${ }^{9,17}$

\section{The future of the GLP-1 RAs}

One of the drawbacks of GLP-1RA therapy has been that it is an injection. Although once-weekly injections are now available compared to the previous twice-daily or oncedaily preparations, future possibilities include an oral preparation of a new GLP-1RA, Rybelsus (semaglutide), which has shown results comparable to the injectable form in Phase 2 trials, with weight loss of $6.5 \mathrm{~kg}$ at 26 weeks. Continuous delivery of up to $80 \mathrm{mg} /$ day of Exenatide via an SC miniature osmotic pump is another future treatment possibility with Phase 2 trials suggesting weight loss of -2.4 to $-4.2 \mathrm{~kg}$ at 48 weeks. Another area for future drug development may be in combination peptides for an additive or synergistic effect. GLP-1 RAs are now widely used in the treatment of T-IIDM and more recently to treat obesity. As GLP-1RAs inhibit glucagon and slow gastric emptying in addition to the incretin effects, several studies assessing the impact of GLP-1RAs in patients with T-IDM are ongoing. Most of the side effects of GLP-1RAs are GIrelated (nausea in particular). However, there remain some concerns about long-term safety, particularly with regard to the possible risk of pancreatitis and/or pancreatic cancer. There are also some concerns due to the increase in heart rate of 2-3 beats/min seen with Liraglutide and Exenatide. Several trials assessing the cardiovascular safety of GLP-1RAs are ongoing, with results from the Evaluation of Lixisenatide in Acute Coronary Syndrome (ELIXA) trial showing no increase in cardiovascular risk or increase in heart rate with Lixisenatide. The use of GLP-1RAs off licence is common, but further studies need to address this gap. Although, Saxenda (liraglutide) is approved for the treatment of obesity regardless of T-IIDM, its place in the treatment algorithm in real life and its cost effectiveness remain to be determined. ${ }^{30}$

\section{CONCLUSION}

Diabetes and obesity are chronic disorders that are on the rise worldwide. BMI has a strong relationship to diabetes and insulin resistance. Insulin resistance with impairment of $\beta$-cell function leads to the development of diabetes. NEFAs is a cornerstone in the development of insulin resistance and in the impairment of $\beta$-cell function. New approaches in managing and preventing diabetes in obese 
individuals must be studied and investigated based on these facts. Agents in the GLP-1 receptor agonist class are effective treatment options for patients with T-IIDM, achieving reductions in $\mathrm{HbA}_{\mathrm{c}}$ and body weight as monotherapy or add-on to other anti-hyperglycaemic therapies. Helping patients establish realistic expectations and providing education about how the medication works are important to help ensure desired outcomes.

\section{REFERENCES}

1. Parmar MY. Review: Obesity and type 2 diabetes mellitus 2018. Integr Obesity Diabetes 4(4).

2. Alan J. Garber. Long-Acting Glucagon-Like Peptide 1 Receptor Agonists. Diabetes Care 2011, 34(supp 2), S279-S284.

3. Pouya Saeedi, Inga Petersohn, Paraskevi Salpea, Belma Malanda, Suvi Karuranga, Nigel Unwin, Stephen Colagiuri, Leonor Guariguata, Ayesha A. Motala, Katherine Ogurtsova, Jonathan E. Shaw, Dominic Bright, and Rhys Williams. On behalf of the IDF Diabetes Atlas Committee. Global and regional diabetes prevalence estimates for 2019 and projections for 2030 and 2045: results from the IDF Diabetes Atlas. $9^{\text {th }}$ edition. 2019.

4. Kirti Kaul, Joanna M. Tarr, Shamiml. Ahmad, Eva M. Kohner, and Rakesh Chibber. Introduction to Diabetes Mellitus. Advances in experimental medicine and biology. 771, 2012, PP1-11.

5. Abdullah S Al-Goblan, Mohammed A Al-Alfi, and Muhammad Z Khan. Mechanism linking diabetes mellitus and obesity. 7, 2014, 587-591

6. Diabetes Mellitus (DM). By Erika F. Brutsaert. 2019

7. American Diabetes Association. Standards of medical care in diabetes-2018. Diabetes Care 41(suppl 1), 2018, S31-S59.

8. Rodbard HW, Blonde L, Braithwaite SS, et al; AACE Diabetes Mellitus Clinical Practice Guidelines Task Force. American Association of Clinical Endocrinologists medical guidelines for clinical practice for the management of diabetes mellitus. Endocr Pract 13(suppl 1), 2007, 1-68.

9. Wei $B$, Huang $X$, and Liang M. Effect of Glucagon like Peptide -1(GLP1) on Vol.5, No.1, Obesity. 2018, 4.

10. WHO Fact sheet N 311. Obesity and overweight. 2015.

11. Elmien Bronkhorst and Natalie Schellack. Liraglutide for the treatment of obesity. South African Family Practice 58(3), 2016, 3840.

12. Bhat SP and Sharma A. Current drug targets in obesity pharmacotherapy-A review. Curr Drug Targets 18, 2017, 983-993.

13. Nathan DM, Buse JB, Davidson MB, et al. Medical management of hyperglycaemia in type 2 diabetes mellitus: a consensus algorithm for the initiation and adjustment of therapy: a consensus statement from the American Diabetes Association and the European Association for the Study of Diabetes. 52, 2009, 17-30.

14. Rodbard HW, Jellinger PS, Davidson JA, et al. Statement by an American Association of Clinical Endocrinologists/American College of Endocrinology consensus panel on type 2 diabetes mellitus: an algorithm for glycemic control. 15, 2009, 540-559.

15. Rehfeld JF. The Origin and Understanding of the Incretin Concept. 2018, Frontiers in Endocrinology. 9, 387.

16. Rang HP, Ritter JM, Flower R, and Henderson G. 2016. Rang and Dale's Pharmacology (8th ed.). United Kingdom: Elsevier Churchill Livingstone. p. 385.

17. Katrine B Hansen, Tina Vilsboll, and Filip K Knop. Incretinmimetics: a novel therapeutic option for patients with type 2 diabetes - a review. Diabetes, Metabolic Syndrome and Obesity: Targets and Therapy 2010, 3, 155-163.

18. Salih Sanlioglu, Hale M. Tasyurek, Hasan Ali Altunbas, and Mustafa Kemal Balci. Incretins: Their physiology and application in the treatment of diabetes mellitus. Diabetes Metab Res Rev 30, 2014, 354-371.

19. Incretin Mimetics (GLP-1 Agonists), Diabetes.co.uk-the global diabetes community. 2019.

20. Baggio LL. Glucagon-like Peptide-1 Analogs Other Than Exenatide. 2008. Medscape Diabetes and Endocrinology.

21. American Diabetes Association. Standards of medical care in diabetes-2012. Diabetes Care 35 Suppl 1, 2012, S11-63.

22. Das, Anju; Geetha, K. M.; Hazarika, Iswar. 2019. Contemporary Updates on the Physiology of Glucagon like Peptide-1 and Its Agonist to Treat Type 2 Diabetes Mellitus. International Journal of Peptide Research and Therapeutics.

23. Deborah Hinnen. Glucagon-Like Peptide 1 Receptor Agonists for Type 2 Diabetes. Diabetes Spectrum 30(3), 2017, 202-210

24. Stefanie Amarens de Boer, Joop Daniel Lefrandt, Japke Frida Petersen, Hendrikus Hessel Boersma, Douwe Johannes Mulder, and Klaas Hoogenberg. The effects of GLP-1 analogues in obese, insulinusing type 2 diabetes in relation to eating behaviour. Int J Clin Pharm 38, 2016, 144-151.

25. Matteo Monami, Ilaria Dicembrini, Niccolo Marchionni, Carlo M. Rotella, and Edoardo Mannucci. Effects of Glucagon-Like Peptide-1 Receptor Agonists on Body Weight: A Meta-Analysis. 2012, 8 pages.

26. Chakraborti CK. Exenatide: a new promising antidiabetic agent. Indian J Pharm Sci. 72(1), 2010, 1-11.

27. James Crane and Barbara McGowan. The GLP-1 agonist, liraglutide, as a pharmacotherapy for obesity. Ther Adv Chronic Dis. Vol. 7(2), 2016, 92-107.

28. Bronislava R. Gedulin, Svetlana E. Nikoulina, Pamela A. Smith, George Gedulin, Loretta L. Nielsen, Alain D. Baron, David G. Parkes, and Andrew A. Young. Exenatide (Exendin-4) Improves Insulin Sensitivity and -Cell Mass in Insulin-Resistant Obese fa/fa Zucker Rats Independent of Glycemia and Body Weight. 146(4), 2004, 2069 2076.

29. Lotte Bjerre Knudsen. Inventing Liraglutide, a Glucagon-Like Peptide-1 Analogue, for the Treatment of Diabetes and Obesity. ACS Pharmacology \& Translational Science 2 (6), 2019, 468-484.

30. Milan K Piya, Shujah Dar, and Abd A Tahrani. The role of GLP-1 receptor agonists as weight loss agents. Practical Diabetes 32(8), 2015, 297-300.

Source of Support: None declared.

Conflict of Interest: None declared.

For any question relates to this article, please reach us at: editor@globalresearchonline.net

New manuscripts for publication can be submitted at: submit@globalresearchonline.net and submit_ijpsrr@rediffmail.com 